\title{
A CASE OF DISEASE OF NERVOUS SYSTEM, PRESENTING SYMPTOMS OF TUMOUR IN WHICH ONLY MICROSCOPICAL CHANGES WERE FOUND.
}

\author{
Br WALTFR BERNARD, F.K.Q.C.P.
}

[Read before the Section of Pathology, January 13, 1888.]

ON 16th February, 1887, Mary Stewart, aged twenty, was first seen.

History.-In November, 1886, she noticed her sight commencing to fail. At that time she had "soreness" in her forehead and a little "dizziness." Her mother told us she "could not thread a needle three weeks before Christmas." On 9th February, 1887 bilious vomiting set in. She had great difficulty in walking, and her sight was very defective.

On February 16 th we found her in bed. Face was ruddy; body well nourished; knee-jerks exaggerated on both sides, particularly on right; ankle-clonus easily elicited on right side, not on left; pupils large, acting very little, if at all, to light; no nystagmus; left dise normal; right disc moderately inflamed; sleeps a good deal; mind seems clear, and she answers sensibly any questions put to her. Vomiting is complained of. Has never had a discharge from the ear. No ptosis. Can look in any direction, but is slow in moving her eyes. Menstruation normal. Cannot count fingers. Has some pain in her forehead. Family history throws no light on case. No history of tubercle or nervous disease.

February 23rd.-Patient drowsy. Vomiting still present. On 20 th she, for the first time, passed her urine in bed; since 19th has had no pain in her head.

26th.-Patient very drowsy. Answers slowly when asked any questions. Pulse 84, small and weak. Head, when she lies on back, tends to turn to right side. Yawns frequently. Passes urine and frees in bed. 
March 2nd.-Neck is stiff. Head is turned to right side; she does not like to have it moved from this position, as it gives her pain.

5th.-When awake she has a peculiar staring look. This is from retraction of the upper eyelids. The mother says they appear "as if they were catched up ;" vomiting has ceased; kncejerks are not now exaggerated on either side; ankle-clonus still present on right side.

12th.-Right disc moderately inflamed; left disc odematous on its nasal side; ankle-clonus could not be elicited; saliva comes from one angle of the mouth.

16th.-Knee-jerk is absent on right side-present slightly on left side; complains of soreness in front part of neck; there is tenderness here, but no swelling.

23rd.-Does not notice when the finger is brought close up to the eye; nasal side of left disc inflamed.

26 th-Upper eyelids are not now retracted; vomiting laas returned. Mother says, on the 25 th she had an "attack of nerres" in her throat.

30th.-Patient knows when the hand is wared before her eyes; temperature is subnormal; sphincters have to a great extent recovered. Was sitting up in a chair.

April 9th.-Has her legs drawn up; it pains her to get them stretched down.

20th.-We found that right arm has very litrle power in it. On 18th April she had two fits; she "worked" a little in thell. After fits she vomited a large quantity of green matter.

23rd.-She was found in a fit; she was quite unconscious, but not convulsed; eyes were turned up; she was pale and changerl colour somewhat. Mother attributes this fit to her bowels being confined and the administration of an enema by a nurse.

May 11th.-There is marked nystagmus. Her eyes tend more to left than to right. Her mind is affected. She fancies she is not in bed but on her feet.

14th.-Eyes tend towards left; oscillate from side to side about 42 times in the minute; movement is rapid towards right, slower 
towards left. The excursion of the eyes is not great, and when furthest towards right barely look straight forward.

21st.-Cannot look to right; with an effort she can look straight forward. Left upper eyelid follows eye downward less than right. Left arm is weak, but is not so bad as right.

28th. -Eyes do not oscillate as frequently; are not looking so much to left, and can move better towards right. Can turn her head to either side without difficulty. Legs still drawn up. It hurts her to have them straightened. Optic neuritis in right eye is subsiding. Temporal edge can be defined by direct method.

June 4th.-Is looking quite straight. Can look to both sides fairly well. Nystagmus still present. Is menstruating for first time since early part of illness.

11th.-Complains of pains in her knees; legs are drawn up. Her mother told us she has some pain in her head occasionally.

22 nd.- In right eye the neuritis has almost completely subsided, and disc is whitish. The swelling on nasal side of left disc has also subsided. Has control over rectum and bladder. Left arm is very weak ; she cannot put it up to her head; can put up right without any difficulty.

July 9th.- She was found asleep. On npening eyelids pupils were found considerably contracted. When she awoke pupils immediately dilated, and remained large. With left eye she can count fingers. During sleep there was no nystagmus.

23rd.-Nystagmus very slight-rotatory. Dr. M'Caul was obliged to draw off urine. She died of exhaustion on the 8th August, 1887. She could speak four hours before death, and could swallow to the last.

Post-mortem was made next day. Brain and part of cord were examined. Membranes were found to be normal. Brain was no fully examined until hardened by alcohol. No tumour was found anywhere. Ventricles were not dilated. Kight optic nerve shows evidence of neuritis. I show you parts of brain and cord which you can examine for yourselves. Parts of some sections do no take up the stain of logivood, probably on account of defect in the 
stain. In the cervical part of the spinal cord one anterior horn was found atrophid. In the medulla there were found amyloid bodies in abundance, and some evidence of sclerosis.

Remarks. -Dr. Hughlings Jackson reports a case in which symptoms of tumour were present during life, but after death only microscopical changes in the substance of the cortex were found. (See "Fagge's Medicine," 2nd edition, vol. I., p. 630). The case recorded above in some particulars resembles Dr. H. Jackson's case. 